\title{
O DESENVOLVIMENTO NACIONAL E O PARADIGMA DO RULE OF
} LAW

\section{O NATIONAL DEVELOPMENT AND O PARADIGM DO RULE OF LAW}

\author{
KLEBER GIL ZECA
}

Mestrando em Direito Empresarial e Cidadania pelo Centro Universitário Curitiba UNICURITIBA

\section{RESUMO}

Este artigo visa analisar de que forma o desenvolvimento nacional pode ser alcançado no Brasil e qual a participação do direito e o grau de intervenção estatal na economia para tal desiderato. Por meio de pesquisa bibliográfica, busca-se a correlação entre a ordem econômica e o direito econômico, suas fontes teóricas e fundamentos. Dessa correlação, parte-se para a análise econômica do direito e do desenvolvimento nacional preconizado pela Carta Política brasileira e chega-se até as concepções econômicas do rule of Law. Conclui-se que os ideais neoliberais alienígenas decorrentes de "boas práticas de governança" em países desenvolvidos não podem ser transportados para nosso país sem adaptações à nossa cultura, para que o aparato institucional e as políticas públicas do Estado Social sejam adequados à nossa realidade.

PALAVRAS-CHAVE: Livre concorrência; Livre iniciativa; Defesa do consumidor; Intervenção estatal; Estado Social; Políticas econômicas; Desenvolvimento econômico; Desenvolvimento Social. 
Personalidade Acadêmica Homenageada:

Florisbal de Souza Del'Olmo (Professor Convidado - UNICURITIBA)

\section{ABSTRACT}

This article aims to analyze how national development can be achieved in Brazil and what the participation of the law and the degree of the state intervention in the economy for such pretension. Through a bibliographical research, the correlation between the economic order and the economic law, its theoretical sources and fundamentals is sought. From this correlation, one starts with the economic analysis of the law and the national development advocated by the Brazilian Political Charter, and one reaches up to the economic conceptions of the rule of Law. It is concluded that neoliberal alien ideals stemming from "good governance practices" in developed countries can not be transported to our country without adaptations to our culture, so that the institutional apparatus and public policies of the Social State are adequate to our reality.

KEYWORDS: Free competition; Free Initiative; Consumer defense; State intervention; Social State; Economic policies; Economic development; Social development.

\section{INTRODUÇÃO}

As relações sociais num Estado de direito contemporâneo são reguladas por princípios, valores e normas jurídicas que disciplinam o que pode ou não pode ser feito pelos indivíduos de uma sociedade, assim como determinam as sanções pelo desrespeito de regras que causam conflitos sociais.

Neste sentido, o Estado Democrático de Direito é uma estrutura jurídica que estabelece limitadores de conduta dos membros de uma determinada sociedade em nome do desenvolvimento intersubjetivo do grupo social (FRANÇA, 2016).

Pode-se dizer que o Estado tem esse poder sobre o indivíduo porque este permite perder um pouco de sua "liberdade" em prol da sociedade, transferindo ao 


\section{Personalidade Acadêmica Homenageada:}

Florisbal de Souza Del'Olmo (Professor Convidado - UNICURITIBA)

Estado o poder de regular as condutas sociais para consecução dos fins comuns da sociedade e proteger os indivíduos ou grupos sociais mais necessitados.

O desenvolvimento social implica em melhoria do bem-estar social, ou seja, melhoria na qualidade de vida dos indivíduos.

Conforme Paulo Bonavides em seu livro "Do Estado liberal ao Estado Social" (2007), nos primórdios do Estado Liberal, quando o sistema capitalista fundou seus alicerces baseados na propriedade privada e na liberdade de comércio com vista ao lucro, principalmente em favor dos burgueses que então buscavam direitos como liberdade e igualdade, o Estado deveria intervir apenas quando ocorressem conflitos sociais entre os civis, bem como deveria manter a estrutura de segurança pública e de defesa externa da nação, não intervindo diretamente na ordem econômica capitalista.

Com a evolução da sociedade capitalista e do Estado de Democrático de Direito, o Estado Liberal cedeu espaço ao Estado Social, haja vista que o capitalismo liberal, tido como capitalismo "selvagem", não atendia igualmente aos anseios de todas as classes da sociedade em matéria de desenvolvimento social, perpetrando as diferenças entre classes sociais que já existiam à época da Revolução Francesa.

Desta maneira, o Estado Social passa a ter, entre outras, a função de "ajustar" desvios da economia e, para tanto, muitas relações econômicas passam a ser reguladas pelo Direito.

A Carta Política de 1988 já em seu artigo 1ํ, inciso IV, determina que a livre iniciativa é fundamento do Estado Democrático de Direito. Contudo, logo no artigo $3^{3}$, onde são estabelecidos os objetivos da República, parte constituinte do Estado Democrático de Direito, encontramos os objetivos de garantir o desenvolvimento nacional, erradicar a pobreza e a marginalização, reduzir as desigualdades sociais e regionais, assim como promover o bem de todos.

Cabe aqui ressaltar que até a Constituição de 1967, o bem protegido era o "desenvolvimento econômico" (inciso V do artigo 157), mas a partir da Emenda Constitucional de 1969, ficou definido que o "desenvolvimento nacional" seria o bem 
Personalidade Acadêmica Homenageada:

Florisbal de Souza Del'Olmo (Professor Convidado - UNICURITIBA)

tutelado (inciso $\mathrm{V}$ do artigo 160), caracterizando uma mudança conceitual importante.

Pretende-se neste artigo analisar de que forma o desenvolvimento nacional pode ser alcançado no Brasil, qual a participação do direito e o grau de intervenção estatal na economia para alcançarmos tal objetivo.

\section{A ORDEM ECONÔMICA E O DIREITO ECONÔMICO}

Desde a Revolução Francesa a primazia do capitalismo é o livre comércio e a propriedade privada dos meios de produção, objetivando o acúmulo de riquezas, com um mínimo de intervenção estatal na economia.

No Brasil não poderia ser diferente, tanto que o legislador brasileiro, desde a Constituição de 1934, teve a preocupação de regular a intervenção do Estado no domínio econômico, cujo artigo 114 assim preconizava:

A ordem econômica deve ser organizada conforme os princípios da Justiça e as necessidades da vida nacional, de modo que possibilite a todos existência digna. Dentro desses limites, é garantida a liberdade econômica.

Já no regime autoritário do Estado Novo, decorrente do golpe de Estado de 1937, uma nova Constituição foi promulgada, a qual inovou na área econômica com o seguinte enunciado:

Art. 135 - Na iniciativa individual, no poder de criação, de organização e de invenção do indivíduo, exercido nos limites do bem público, funda-se a riqueza e a prosperidade nacional. A intervenção do Estado no domínio econômico só se legitima para suprir as deficiências da iniciativa individual e coordenar os fatores da produção, de maneira a evitar ou resolver os seus conflitos e introduzir no jogo das competições individuais o pensamento dos interesses da Nação, representados pelo Estado. A intervenção no domínio econômico poderá ser mediata e imediata, revestindo a forma do controle, do estimulo ou da gestão direta.

Mesmo no regime autoritário prevalecia a livre iniciativa individual, legitimando a intervenção do Estado no domínio econômico apenas para suprir 


\title{
Personalidade Acadêmica Homenageada:
}

Florisbal de Souza Del'Olmo (Professor Convidado - UNICURITIBA)

deficiências da iniciativa individual e coordenar os fatores de produção, ou seja, a liberdade de iniciativa era amplamente protegida pelo direito, desde que respeitado o bem público e a prosperidade nacional.

As Cartas Constitucionais de 1946 e do período do regime militar seguiram a mesma linha em relação à ordem econômica.

Os fundamentos do Estado Democrático de Direito e os objetivos da República previstos na atual Carta de 1988 já foram expostos no capítulo anterior e, em relação à ordem econômica, o artigo 170 determina o seguinte:

\begin{abstract}
Art. 170. A ordem econômica, fundada na valorização do trabalho humano e na livre iniciativa, tem por fim assegurar a todos existência digna, conforme os ditames da justiça social, observados os seguintes princípios: I soberania nacional; II - propriedade privada; III - função social da propriedade; IV - livre concorrência; V - defesa do consumidor; VI - defesa do meio ambiente, inclusive mediante tratamento diferenciado conforme 0 impacto ambiental dos produtos e serviços e de seus processos de elaboração e prestação; (Redação dada pela Emenda Constitucional no 42 , de 19.12.2003) VII - redução das desigualdades regionais e sociais; VIII busca do pleno emprego; IX - tratamento favorecido para as empresas de pequeno porte constituídas sob as leis brasileiras e que tenham sua sede e administração no País. (Redação dada pela Emenda Constitucional no 6, de 1995). Parágrafo único. É assegurado a todos o livre exercício de qualquer atividade econômica, independentemente de autorização de órgãos públicos, salvo nos casos previstos em lei.
\end{abstract}

Fica patente na atual Carta Política do Brasil que a ordem econômica tem por fim assegurar a todos existência digna, fundada na valorização do trabalho humano e na livre iniciativa para qualquer atividade econômica. É o capitalismo a serviço do desenvolvimento social.

A juridicização da ordem econômica como política econômica é objeto do Direito Econômico. O conceito e objeto do Direito Econômico foram tratados por Washington de Sousa, por ocasião da Conferência inaugural do "Primeiro Seminário Paulista do Direito Econômico", realizado de 6 a 23 de maio de 1975 em São Paulo, segundo o qual considera

O Direito Econômico, um conjunto de normas de conteúdo econômico que pelo princípio da economicidade assegura a defesa e a harmonia dos interesses individuais e coletivos, bem como regulamenta a atividade dos 


\section{Personalidade Acadêmica Homenageada:}

\section{Florisbal de Souza Del'Olmo (Professor Convidado - UNICURITIBA)}

respectivos sujeitos na efetivação da política econômica definida na ordem jurídica (SOUSA, 1976, p. 26).

Consoante o referido autor, o Direito Econômico é o ramo do direito que tem por escopo, entre outros, a delimitação da intervenção na economia pelo Estado, a regulamentação da atividade dos agentes econômicos e a melhoria de circulação dos fatores de produção, conforme o sistema econômico adotado.

A intervenção do Estado pode se dar por meio de instrumentos de regulação econômica, tais como agente econômico (bancos públicos de fomento), monopólio de determinadas atividades econômicas de interesse nacional, agências reguladoras, política de incentivos fiscais ou estruturais, além da utilização dos impostos como forma de intervenção para garantir o desenvolvimento nacional.

Então, o Direito Econômico tem uma relação multidisciplinar e de interdependência com a ciência Econômica, servindo como elo jurídico entre o sistema econômico e a política econômica.

Esta ligação jurídica tem como base o disposto nos artigos iniciais da nossa Carta Política, quando trata dos objetivos da República em garantir o desenvolvimento nacional, erradicar a pobreza, a marginalização, reduzir as desigualdades sociais e promover o bem de todos, assim como quando trata da livre iniciativa e dos valores sociais do trabalho como alguns dos fundamentos do Estado Democrático de Direito.

O Direito Econômico não se confunde com Direito Tributário, Administrativo ou Civil, por exemplo. Ele segue, conforme definição de Sousa, o princípio da economicidade, o qual "assegura a defesa e a harmonia dos interesses individuais e coletivos, bem como regulamenta a atividade dos respectivos sujeitos na efetivação da política econômica definida na ordem jurídica" (SOUSA,1976, p. 26).

O princípio da economicidade defendido por Sousa é um instrumento hermenêutico que visa à busca do "justo-certo, capaz de adequar a conduta econômica a normas jurídicas que impeçam rompimentos do equilíbrio ou o estabelecimento de conflitos de interesses" (SOUSA,1976, p. 27, grifo do autor). 
Personalidade Acadêmica Homenageada:

Florisbal de Souza Del'Olmo (Professor Convidado - UNICURITIBA)

Assim, a análise do fato jurídico-econômico deverá ser interpretada pelo Direito Econômico por meio da ideologia constitucional que deve ser incorporada na política econômica, com o fim de alcançar os objetivos propostos.

Mais uma vez, Sousa esclarece que

[P]ela "economicidade", isto é, pela racionalidade baseada na ideologia adotada e traduzida na Política Econômica, é que se compreendem tais posições. Nela situa-se a explicação do fato de se controlar o poder econômico privado, mesmo no modelo liberal, impedindo-o de infringir os seus princípios fundamentais. (SOUSA,1976, p. 29)

Este conceito de Direito Econômico proposto por Sousa foi revisto e complementado por ele mesmo algumas vezes depois, conforme nos demonstra Suzy Cavalcante Koury. A primeira revisão, segundo Koury, foi na obra "Primeiras Linhas de Direito Econômico", lançada pela Fundação Brasileira de Direito Econômico no ano de 1977. A segunda revisão foi no livro "Direito Econômico", de 1980 , onde Sousa

Demonstrou ter avançado no conceito de Direito Econômico para considerálo "o ramo do Direito, composto por um conjunto de normas de conteúdo econômico e que tem por objeto regulamentar as medidas de política econômica referentes às relações e interesses individuais e coletivos, harmonizando-as - pelo princípio da 'economicidade' - com a ideologia adotada na ordem jurídica. " (KOURY, 2013, pp. 452-453)

Mesmo nos conceitos mais avançados de Direito Econômico o princípio da economicidade continua a ser balizador da interpretação jurídico-econômica, não se limitando às simples concepções correntes do econômico, da rentabilidade ou do lucro, mas uma interpretação jurídica consubstanciada na ideologia jurídicoeconômica.

Mas, o Direito Econômico, como conjunto de normas de conteúdo econômico, define o princípio da economicidade ou é a economia que define o Direito Econômico?

Na realidade, o artigo 170 da nossa Carta Política traz a fundamentação da ordem econômica e os princípios adotados pelo povo, por intermédio de seu 


\title{
Personalidade Acadêmica Homenageada:
}

Florisbal de Souza Del'Olmo (Professor Convidado - UNICURITIBA)

representante constituinte, de forma que o Direito Econômico deve seguir o princípio definido na Constituição Federal e não o contrário.

Por outro lado, o conteúdo programático do artigo 170, mencionando diversos princípios que devem ser observados pela ordem econômica, traduz, no dizer de Marcelo Neves, uma constituição simbólica, haja vista que está muito mais carregada de expressão político-ideológica, na tentativa de confirmar valores sociais, do que eficácia instrumental-normativa (NEVES, 1996, p. 324).

Conforme Neves, o texto constitucional deve ser entendido como orientação das expectativas e o direcionamento das condutas na esfera pública de acordo com o modelo normativo constitucional (NEVES, 1966, p. 323). Então, os princípios apresentados no artigo 170 da Carta Magna, entre eles, livre concorrência, defesa do consumidor, propriedade privada, função social da propriedade, defesa do meio ambiente e a busca do pleno emprego, necessitam de eficácia instrumentalnormativa para que não fiquem na expressão simbólica do texto, haja vista que, segundo o autor,

\begin{abstract}
A situação social correspondente ao modelo constitucional simbólico só poderia tornar-se realidade mediante uma profunda transformação da sociedade. Ou o figurino constitucional atua como ideal, que por meio dos "donos do poder" e sem prejuízo para os grupos privilegiados deverá ser realizado, desenvolvendo-se, então, a fórmula retórica da 'boa intenção' do legislador constituinte e dos governantes em geral (cf. Schindler, 1967: 66s) (NEVES, 1996, p. 326).
\end{abstract}

Para que os princípios da ordem econômica não sejam simbólicos e que a justiça econômica seja alcançada, o Direito Econômico, que se fundamenta na ética e na política, deve ser capaz de induzir uma profunda transformação da sociedade, em especial da classe empreendedora, a qual deverá realmente aceitar tais princípios como forma de alcançar o desenvolvimento social baseado no desenvolvimento econômico. 
Personalidade Acadêmica Homenageada:

Florisbal de Souza Del'Olmo (Professor Convidado - UNICURITIBA)

\section{ANÁLISE ECONÔMICA DO DIREITO E DESENVOLVIMENTO SOCIAL}

Nos capítulos anteriores foi visto que as relações econômicas passaram a ser mais detidamente objeto do Direito com a transição do Estado Liberal ao Estado Social, culminando no Direito Econômico como ramo de direito autônomo.

Foi dito também que o Direito, como ciência, regulamenta as relações sociais, ou melhor, os comportamentos dos indivíduos de uma sociedade e que o Direito Econômico regulamenta as políticas econômicas de interesse público com base no princípio da economicidade.

A Economia, segundo Ivo Teixeira Gico Jr (2010, p. 17), "é a ciência que estuda como o ser humano toma decisões e se comporta em um mundo de recursos escassos e suas consequências".

Ainda segundo Gico Jr. (2012, p. 7), a economia evolutiva considerava que os mercados em competição tenderiam à eficiência e, da mesma forma, à geração de instituições eficientes. Por esta concepção econômica, segundo o autor, a escassez geraria a concorrência, as instituições mais eficientes sobreviveriam às ineficientes e às incapazes de satisfazer as necessidades humanas no longo prazo, e que a racionalidade dos agentes econômicos, moldados pela concorrência do mercado, seria suficiente para correção de eventuais comportamentos desviantes, superando os atritos ao longo prazo.

Nessa concepção da economia evolutiva, as normas jurídicas e outros institutos não seriam relevantes para o equilíbrio econômico ou à eficiência no longo prazo, pois o mercado se autorregularia independentemente das instituições jurídicas.

O problema da concepção da economia evolutiva é que o ser humano toma decisões e se comporta na sociedade com recursos escassos pelo menor custo de transação possível, com base em informações que encontra ou possui à sua disposição. Diante disto, é muito provável que o agente econômico tome decisões erradas a ponto de causar comportamentos desviantes viciosos capazes de impedir 


\section{Personalidade Acadêmica Homenageada:}

\section{Florisbal de Souza Del'Olmo (Professor Convidado - UNICURITIBA)}

ou dificultar a superação dos atritos no longo prazo pela própria economia de mercado.

A economia moderna, por outro lado, com uma leitura neoinstitucionalista, entende que os institutos jurídicos e políticos externos à economia podem interferir na tomada de decisão dos agentes econômicos e nos seus comportamentos de forma a, inclusive, colaborar com o desenvolvimento econômico e nacional (GICO JR., 2012, p. 6-7).

Esta nova constatação da Nova Economia Institucional - NEl decorre, em parte, da Análise Econômica do Direito - AED, considerada por Gico Jr. (2010, p. 17-18) como

\footnotetext{
O campo do conhecimento humano que tem por objetivo empregar os variados ferramentais teóricos e empíricos econômicos e das ciências afins para expandir a compreensão e o alcance do direito e aperfeiçoar 0 desenvolvimento, a aplicação e a avaliação de normas jurídicas, principalmente com relação às suas consequências.
}

Portanto, a AED é um método econômico de análise de qualquer decisão humana juridicamente relevante, decorrente ou não de recursos escassos, e não apenas aquelas ligadas diretamente ao lucro, rentabilidade e trocas de bens ou serviços, que leva em consideração o custo de oportunidade da decisão tomada em relação à alternativa preterida.

O método da AED supõe que os agentes econômicos tomam suas decisões racionalmente com base no menor custo que atenda ao seu maior benefício (racionalidade maximizadora).

Neste sentido, a AED visa prever as consequências de determinado arcabouço normativo no mundo fático econômico (AED positiva) ou, partindo do mundo fático econômico, determinar quais normas jurídicas necessitam ser adotadas (AED normativa).

$\mathrm{Na}$ AED positiva, investiga-se um fato (o que é) e determina-se a consequência, tal qual um juiz faz em sua sentença. Já a AED normativa investiga um valor (o que deve ser) e quais seriam as consequências necessárias (sanção ou incentivo, por exemplo) que devem ser regulamentadas pelo Direito. 


\section{Personalidade Acadêmica Homenageada:}

\section{Florisbal de Souza Del'Olmo (Professor Convidado - UNICURITIBA)}

É possível dizer que a AED está intimamente ligada ao Direito Econômico, mas com este não se confunde, muito embora ambos possam ter objetivos comuns, entre eles a busca do desenvolvimento econômico e do desenvolvimento social. A AED normativa pode auxiliar inclusive em políticas econômicas a serem implantadas pelo Direito Econômico, considerando a racionalidade maximizadora dos agentes econômicos e os incentivos ou as sanções decorrentes da norma jurídica proposta.

De acordo com Gico Jr. (2011, p. 24-25), o comportamento racional maximizador num mercado livre "levará os agentes a realizar trocas até que os custos associados a cada troca se igualem aos benefícios auferidos, momento a partir do qual não mais ocorrerão trocas", conhecido como equilíbro.

O referido equilíbrio decorre do livre mercado e quando é alcançado, diz-se que mercado eliminou todos os desperdícios, tornando-se eficiente, conhecido como Pareto-eficiente, ou ótimos de Pareto (GICO Jr. 2011, p. 25).

Segundo Mario Gomes Schapiro (2010, p. 217) a NEl foi a escola econômica que introduziu na teoria econômica de matriz neoclássica as instituições como variável da análise econômica. Esta escola, defendendo que a racionalidade dos agentes é limitada, conclui que as relações econômicas são reguladas por aparatos institucionais, como a propriedade e o contrato e suas garantias jurídicas e que na ausência destes aparatos, os negócios podem não se consumar. A partir da internalização das instituições como variáveis da análise econômica, os estudiosos passaram a investigar a relação entre o desempenho econômico dos países e a qualidade dos respectivos ambientes institucionais, entre eles as normas jurídicas e as respostas do Judiciário.

Contudo, tais estudos continuavam com os pressupostos da economia clássica, como o individualismo metodológico e a primazia do mercado, compreendendo as instituições como aparatos reguladores externos e não constitutivos do mercado (SCHAPIRO, 2010, p. 218).

Esta premissa deu causa ao paradigma do rule of Law no desenvolvimento econômico, pelo qual, considerando o ambiente jurídico-institucional como uma variável externa à dinâmica social, seria possível realizar-se "transplantes 


\section{Personalidade Acadêmica Homenageada:}

Florisbal de Souza Del'Olmo (Professor Convidado - UNICURITIBA)

institucionais" de países que apresentaram sucesso no campo do desenvolvimento econômico para países em desenvolvimento.

Neste contexto, a partir da década de 1990, pesquisadores econômicos passaram a relacionar a influência do aparato institucional de cada país sobre as decisões dos agentes econômicos com o potencial de crescimento econômico nacional.

As agências internacionais de fomento, que antes promoviam ou financiavam obras de infraestruturas e programas de investimento público nos países subdesenvolvidos, passaram a focar seus esforços de intervenção no reaparelhamento das instituições das nações em desenvolvimento, criando a noção de rule of Law como um conjunto definido de concepções econômicas, interpretações jurídicas e estratégicas políticas para a promoção do desenvolvimento econômico dos países ainda subdesenvolvidos (SCHAPIRO, 2010, p. 216 - apud TRUBEK; SANTOS, 2006).

As concepções econômicas do rule of Law criaram o paradigma de desenvolvimento econômico no qual as transações econômicas privadas são lastreadas pelos institutos da propriedade privada e da segurança dos contratos, os quais são garantidos pelas instituições jurídicas e pelas políticas públicas do país comprometidas em garantir o espaço do mercado livre como alocador de recursos, sem a interferência direta do Estado na economia.

Este modelo de desenvolvimento econômico do rule of Law era composto basicamente pela determinação de "instituições corretas" e de "boas práticas de governança" constatadas em países desenvolvidos para serem aplicados, ipsis litteris, nos países pobres e em desenvolvimento.

Como se pode verificar, os atributos jurídico-institucionais do rule of Law necessários para um bom desenvolvimento econômico são normas jurídicas que garantam a livre iniciativa dos agentes econômicos, a propriedade privada, a aplicabilidade dos termos contratuais, assim como a limitação ao mínimo da intervenção estatal, as quais deverão ser asseguradas por um Poder Judiciário 


\title{
Personalidade Acadêmica Homenageada:
}

\section{Florisbal de Souza Del'Olmo (Professor Convidado - UNICURITIBA)}

independente e célere em suas decisões, para diminuir os atritos do mercado o mais rápido possível.

Neste paradigma, temos a primazia do direito privado sobre o direito público no tocante ao desenvolvimento econômico, ao contrário do período desenvolvimentista das décadas de 1950 a 1980, baseado no consenso keynesiano, em que se estimulava uma participação mais ativa do Poder Público nas transações privadas para suprir as falhas do mercado.

A partir da década de 1990, este novo paradigma do rule of law, no qual o aparato institucional "correto" e as "boas práticas de governança" são tidos como a melhor garantia para o desenvolvimento econômico por meio da iniciativa privada, foi fonte para as ideias neoliberais, pois, conforme Schapiro

\begin{abstract}
$\mathrm{Na}$ realidade, a intervenção econômica do estado, que tinha como fundamento o diagnóstico das falhas de mercado, passou a ser modulada pela noção de falhas de governo, isto é, a percepção de que as falhas proporcionadas pela regulação são tão ou mais significativas que as próprias falhas de mercado. (SCHAPIRO, 2010, p. 220).
\end{abstract}

Este paradigma com ideias neoliberais do rule of Law foi sendo empregado a partir da década de 1990 pelas agências mundiais de fomento, principalmente pelo Banco Mundial, a ponto de países, tanto da América Latina, como do Leste Europeu e da África Subsaariana, realizarem diversas reformas jurídico-institucionais baseadas no Rule of Law.

Era esperado que a aplicação nesses países subdesenvolvidos deste modelo de desenvolvimento econômico baseado "na forma de promoção da segurança jurídica, de estímulo ao ambiente privado de negócios e de mitigação das ações interventivas do estado despertaria, por si só, o desenvolvimento econômico e social dos países" (SCHAPIRO, 2010, p. 221 apud Kennedy, 2003, p. 17).

O Brasil promoveu a partir de 1990 reformas econômicas baseadas neste modelo rule of Law que buscaram a diminuição do déficit fiscal, a redução da participação do Estado na economia de forma direta, por meio de privatizações de empresas e instituições financeiras públicas, bem como alterações no processo judicial, visando acelerar as decisões do Poder Judiciário. 


\section{Personalidade Acadêmica Homenageada:}

Florisbal de Souza Del'Olmo (Professor Convidado - UNICURITIBA)

Acontece que o modelo rule of Law parece não ter levado em consideração a existência idiossincrática de condições de mercado e comportamentos dos agentes econômicos de cada nação, como valores culturais, que em muitos casos tornaram ineficazes as recomendações one size fits all do modelo.

Exemplo disto no Brasil é a utilização de bancos públicos para o fomento de investimento econômico, como o BNDES, Banco do Brasil, Caixa Econômica Federal, BNH, entre outros, que seria, de acordo com o modelo, "uma solução alternativa introduzida por governos que são incapazes de estabelecer um ambiente institucional adequado, informado por um regime de proteção da propriedade privada e pela garantia de efetividade dos contratos". (SCHAPIRO, 2010, p. 226).

Em que pese entre os anos de 1990 e 2000 terem sido privatizados um grande número de bancos públicos estaduais e que o sistema bancário nacional tenha recebido bancos privados do exterior para estimular a concorrência, estas políticas públicas não foram o suficiente para "estimular" os bancos privados a entrar no mercado de financiamento de investimento de longo prazo e de maior risco, como acontece com os bancos públicos, em especial o BNDES.

\section{CONCLUSÃO}

Garantir o desenvolvimento nacional é um dos objetivos fundamentais da República Federativa do Brasil, ao lado de outros como erradicar a pobreza e a marginalização, reduzir as desigualdades sociais e regionais, assim como promover o bem de todos.

Neste sentido, é nítido que o desenvolvimento nacional deve ser interpretado como além do mero desenvolvimento econômico, pois deve ser conjugado com benefícios sociais (erradicar a pobreza e as desigualdades sociais, p.ex.) por vezes de difícil consecução por via de uma economia liberal.

O período desenvolvimentista que ocorreu entre as décadas de 1950 a 1980, sob o consenso keynesiano, foi caracterizado, em geral, pela intervenção 


\section{Personalidade Acadêmica Homenageada:}

\section{Florisbal de Souza Del'Olmo (Professor Convidado - UNICURITIBA)}

estatal em obras de infraestruturas, geração de empregos públicos e programas de investimentos com financiamentos públicos - fomentos.

O Brasil teve nesse período um desenvolvimento econômico importante, no qual o governo realizou inúmeras obras de infraestrutura, como rodovias, pontes, usinas hidrelétricas, portos, aeroportos, entre outros. Este tipo de intervenção é relevante porque o mercado nacional, para se desenvolver e ser competitivo com o mercado estrangeiro, necessita reduzir custos, e a infraestrutura logística é um custo indireto que nos países desenvolvidos já está amortizado, diminuindo seus custos e, por consequência, aumentando seus lucros.

Outro tipo de intervenção estatal daquele período foi a criação de empresas públicas com foco em atividades econômicas em áreas de interesse nacional e de alto risco, como exploração de petróleo e outros recursos escassos.

Contudo, numa economia ainda emergente, a arrecadação de impostos, os quais poderiam ser utilizados pelo governo na criação de infraestrutura logística, é insuficiente para dar o suporte logístico ideal e gera um custo econômico adicional se for elevada, podendo causar retração econômica. Desta maneira, o país se viu na obrigação de recorrer a recursos financeiros externos, endividando-se para alavancar o desenvolvimento econômico nacional, pelo menos em tese, até que a economia fosse suficiente para gerar impostos necessários para a quitação das dívidas e a manutenção da infraestrutura realizada pelo endividamento.

Este modelo de intervenção estatal onde o poder público investe em obras de infraestrutura é interessante, mas pode causar distorções quando o governo passa a ser o maior consumidor de serviços, pois o mercado passa a ficar dependente deste "grande" consumidor e pode não mais se equilibrar sem este consumo público.

Para complicar mais, decisões governamentais sobre quais e onde infraestruturas serão construídas podem não convergir com as decisões dos agentes econômicos, que podem optar por outros caminhos para realizar suas transações privadas, sem a utilização da infraestrutura pública posta à disposição da sociedade, causando prejuízos aos cofres públicos pela decisão equivocada. 


\section{Personalidade Acadêmica Homenageada:}

Florisbal de Souza Del'Olmo (Professor Convidado - UNICURITIBA)

Sem contar com o problema do superfaturamento em obras públicas, decorrente da corrupção ativa e passiva, que beneficia somente aos integrantes do esquema corrupto em detrimento de grande parcela da população e demais contribuintes. Outro problema relacionado é o custo de manutenção das infraestruturas públicas quando sob a responsabilidade do Estado, porque, não sendo esta atividade a preocupação principal do governo, é facilmente preterida pela Administração Pública.

Os estudiosos da escola Nova Economia Institucional - NEI perceberam as falhas decorrentes das intervenções estatais direta nas sociedades em desenvolvimento e avaliaram que os riscos das falhas de governo seriam maiores do que os riscos das falhas do mercado capitalista.

Como solução, foram propostos programas de diminuição da participação estatal na economia, restando ao estado garantir os fundamentos básicos do capitalismo, como a propriedade privada, o cumprimento dos contratos, punição às infrações econômicas, dar respostas céleres por parte do Poder Judiciário quando existir conflitos e adotar políticas econômicas no sentido de manter as transações privadas como fonte de alocação de recursos escassos, com vistas ao desenvolvimento econômico.

Este paradigma resultou na noção de rule of law, difundida a partir da década de 1990 pelos organismos internacionais, como Banco Mundial e Nações Unidas - ONU, como forma de incrementar o desenvolvimento econômico por meio do reaparelhamento das instituições.

O Brasil não ficou de fora desta onda neoliberal, tanto que a partir da década de 1990 várias reformas foram feitas visando à diminuição da participação estatal diretamente na economia, como ocorreu com as séries de privatizações, assim como reformas jurídicas no sentido de garantir os fundamentos econômicos do capitalismo.

Mesmo a exploração direta de atividade econômica pelo Estado ficou restrita aos casos de necessidade para a manutenção da segurança nacional ou aos de relevante interesse coletivo, previstos no artigo 173 da Carta Política de 1988. 


\section{Personalidade Acadêmica Homenageada:}

\section{Florisbal de Souza Del'Olmo (Professor Convidado - UNICURITIBA)}

Entre as novas normas jurídicas editadas para garantir a atividade econômica, temos: 1) a lei no 8137/90, que define os crimes contra a ordem tributária, econômica e contra as relações de consumo; 2) a lei $n^{\circ}$ 8.884/94, que dispôs sobre a prevenção e a repressão às infrações contra a ordem econômica; e 3) a lei no 12.529/2011, que alterou a estrutura do Sistema Brasileiro de Defesa da Concorrência e dispõe sobre a prevenção e repressão às infrações contra a ordem econômica.

Estas normas jurídicas visam garantir o combate às infrações econômicas como cartel, preços predatórios ou abusivos, abuso de posição dominante e comportamentos anticompetitivos em geral. Especificamente em relação ao abuso de posição dominante, o Estado criou o Conselho Administrativo de Defesa Econômica - CADE para apuração e repressão dos abusos do poder econômico.

A lei $n^{\circ}$ 12.529/2011, conhecida como lei antitruste, é uma lei que serve de instrumento para a política econômica do Estado intervir na economia privada nos casos de falhas da "lei" de mercado.

Como podemos verificar, o Brasil vem adotando a cartilha neoliberal do rule of law, diminuindo a participação estatal na atividade econômica, garantindo juridicamente os fundamentos do capitalismo e combatendo às infrações econômicas, tidas como falhas do mercado.

O que falta para o desenvolvimento econômico?

Inicialmente, um fator que ainda está faltando na aplicação do rule of Law no Brasil é a questão da excessiva morosidade do Poder Judiciário, assim como de algumas agências reguladoras, como o CADE, nas respostas aos problemas de mercado detectados ou sob análise, ou seja, as infrações econômicas.

A reforma do Judiciário, produzida pela Emenda Constitucional nº 45/2004 e alterações no Código de Processo Civil, incluiu, entre outras alterações, a repercussão geral como requisito de admissibilidade aos Recursos Extraordinários $R E$, cujo objetivo era o de selecionar os RE para análise pelo STF conforme critérios de relevância jurídica, política, social ou econômica. 


\section{Personalidade Acadêmica Homenageada:}

Florisbal de Souza Del'Olmo (Professor Convidado - UNICURITIBA)

Da mesma forma, a lei ำ 11.672/2008, que instituiu o recurso especial repetitivo, e a lei $n^{0} 13.105 / 2015$, que disciplinou tanto o recurso especial quanto o recurso extraordinário repetitivo (arts. 1036 a 1041), tinham tais instrumentos jurídicos por objetivo desafogar o Judiciário e dar efetividade e celeridade ao processo judicial.

Infelizmente, tais soluções jurídicas não foram o suficiente para dar maior celeridade às respostas do Poder Judiciário, causando uma sensação de insegurança jurídica capaz de influenciar negativamente os agentes econômicos ao decidirem realizar suas transações econômicas no nosso país.

Mesmo o CADE, no emblemático caso da concentração econômica envolvendo a aquisição da empresa GAROTO pela empresa NESTLÉ (processo administrativo ํo 08012.001697/2002-89), ocorrida em fevereiro de 2002 e submetida à análise do CADE, a resposta do CADE ocorreu somente dois anos após, decidindo pela desconstituição total do negócio realizado. Esta decisão administrativa foi revogada em primeira instância judicial em 2007 (Ação Ordinária no 2005.34.00.015042-8, da 4⿳亠丷厂 VF/DF) e até o momento aguarda solução definitiva.

A morosidade nas soluções dos litígios tanto administrativos quanto judiciais é um problema institucional que deve ser atacado pelo Estado como um dos principais motivos do entrave ao desenvolvimento nacional, pois que um sistema judicial (e administrativo) bem estruturado contribui para o crescimento econômico e, por consequência, para o desenvolvimento nacional.

Além de focar na reestruturação principalmente processual do Poder Judiciário, outro aspecto relevante para o desenvolvimento nacional são as políticas públicas voltadas para os objetivos republicanos já expostos acima.

Ocorre que qualquer política pública que vise dar subsídios ou incentivos fiscais para determinadas classes sociais ou até mesmo econômicas (as empresas de pequeno porte, p. ex.) depende de arrecadação de impostos de outras áreas ou de outros sujeitos passivos. Portanto, somente o crescimento do volume da economia poderá bancar as políticas públicas de transferências de rendas no longo 


\section{Personalidade Acadêmica Homenageada:}

Florisbal de Souza Del'Olmo (Professor Convidado - UNICURITIBA)

prazo. O endividamento público causado pelo sistema de subsídios não pode se manter por muito tempo sob pena de causar desequilíbrio econômico.

Existe no Brasil, ainda, um grande espaço para o mercado de valores mobiliários, no qual as empresas nacionais podem buscar recursos para seus empreendimentos sem a necessidade de financiamento bancário, seja público, seja privado. Mas este mercado é muito sensível à confiança jurídica de que as infrações econômicas serão devidamente punidas em tempo razoável. Além disso, é um mercado muito suscetível às crises e intervenções políticas e econômicas e somente o tempo pode consolidar a confiança necessária aos operadores econômicos para agirem com mais vigor neste mercado de ações.

No momento atual o BNDES, como banco público, é o maior financiador de investimentos para as empresas no Brasil. Os bancos privados preferem operar em financiamentos mais curtos e de menor risco, com garantias reais.

Neste ponto o paradigma rule of law não serviu ao Brasil. As reformas feitas ao longo das últimas décadas, com privatizações de diversos bancos estatais não foi o suficiente para dar ao mercado financeiro estabilidade para agir sem a presença do Estado, com seus bancos públicos.

Como ensina Schapiro (2010), talvez o mercado econômico brasileiro, por sua cultura e atributos subjacentes à economia, seja diferente do "padrão" e a presença de um banco estatal na economia não seja uma "falha" de mercado a ser combatida.

Para finalizar, relembrando ensinamentos de Marcelo Neves (1996), para que não fiquem no "simbólico", os princípios constitucionais previstos no artigo 170 em relação à ordem econômica devem ser alvo de uma política educacional ao empreendedor (ou ao potencial empreendedor do futuro, as crianças), de forma a causar uma profunda transformação cultural na sociedade, onde o capitalismo conviva com o solidarismo, de forma que toda a sociedade consiga participar e alcançar o desenvolvimento social sonhado. 
Personalidade Acadêmica Homenageada:

Florisbal de Souza Del'Olmo (Professor Convidado - UNICURITIBA)

\section{REFERÊNCIAS}

BONAVIDES, Paulo. Do estado liberal ao estado social. Brasil: Malheiros Editora, $8^{\text {a }}$ Ed. 2007.

CONSELHO ADMINISTRATIVO DE DEFESA ECONÔMICA - CADE. Autos do processo no 08012.001697/2002-89. 2004. Disponível em 11/01/2018 na página eletrônica

https://sei.cade.gov.br/sei/modulos/pesquisa/md pesq processo exibir.php?0c62g2 77GvPsZDAxA01tMiVcL9FcFMR5UuJ6rLqPEJuTUu08mg6wxLt0JzWxCor9mNcMY P8UAjTVP9dxRfPBcTYODL0dQJrH0em4COi5at7KHpCN-QV4eAxdRT24wf8S

CONSELHO ADMINISTRATIVO DE DEFESA ECONÔMICA - CADE. Notícias: Cade analisa proposta de solução para o caso Nestlé/Garoto. 2016. Disponível em 11/01/2018 no endereço eletrônico http://www.cade.gov.br/noticias/cade-analisaproposta-de-solucao-para-o-caso-nestle-garoto

FRANÇA, Phillip Gil. Controle da Administração Pública. 4ํe․ edT. São Paulo. 2016. p. $65-67$

FRANÇA, Phillip Gil. Por que e para quem um Estado? Direito do Estado, Ano 2016, Num. 206, de 06/07/2016, disponível em 11/01/2018 no endereço eletrônico http://www.direitodoestado.com.br/colunistas/phillip-gil-franca/por-que-e-para-quemum-estado

FURTADO, Celso. Criatividade e dependência na civilização industrial. Ed. Definitiva. São Paulo: Companhia das Letras, 2008.

GICO JR. Ivo Teixeira. A tragédia do Judiciário. RDA - Revista de Direito Administrativo, Rio de Janeiro, v. 267 p.163-198, set/dez. 2014. Disponível em http://bibliotecadigital.fgv.br/ojs/index.php/rda/article/viewFile/46462/44453 acessado em 20/12/2017.

GICO JR. Ivo Teixeira. A tragédia do Judiciário: subinvestimento em capital jurídico e sobreutilização do Judiciário. Tese de Doutorado. Departamento de Economia da Universidade de Brasília - UnB. Brasília. 2012. Disponível em http://www.repositorio.unb.br/bitstream/10482/13529/1/2012 IvoTeixeiraGicoJunior.p df acessado em 20/12/2017.

GICO JR, Ivo Teixeira. Introdução à análise econômica do Direito. In RIBEIRO, Marcia Carla Pereira; KLEIN, Vinicius (Coord.). O que é análise econômica do direito: Uma introdução. Belo Horizonte-MG. Ed. Fórum, 2011. p. 17-26. ISBN 97885-7700-468-3

KOURY, Suzy Cavalcante. O Princípio da Economicidade na obra de Washington Peluso Albino de Souza. Revista Faculdade de Direito UFMG, número especial em 
Personalidade Acadêmica Homenageada:

Florisbal de Souza Del'Olmo (Professor Convidado - UNICURITIBA)

Memória do Prof. Washington Peluso Albino de Souza, PP. 443-463, 2013. Disponível em https://www.direito.ufmg.br/revista/index.php/revista/article/viewFile/P.03042340.2013vWAp443/314 Acessado em 20/12/2017.

NEVES, Marcelo. Constitucionalização simbólica e desconstitucionalização fática: mudança simbólica da Constituição e permanência das estruturas reais de poder. Revista de Informação Legislativa. Brasília a.33 n. 132 out./dez. 1996. (fls. 321 a 330). Disponível em 11/01/2018. Pág. eletrônica http://www2.senado.leg.br/bdst/handle/id/176514

NEVES, Marcelo. Entre Têmis e Leviatã: uma relação difícil. O Estado Democrático de Direito a partir e além de Luhmann e Habermas. [tradução do autor] Martins Fontes. São Paulo. 2ª Ed. 2008.

SCHAPIRO. Mario Gomes. Repensando a relação entre Estado, Direito e Desenvolvimento: os limites do paradigma rule of Law e a relevância das alternativas institucionais. Revista Direito GV. São Paulo. 6(1), p.213-252. Jan-Jun 2010.

SOUSA. Washington Peluso Albino de. Conceito e objeto do direito econômico. Revista Faculdade de Direito UFMG. V. 24, no 16, Belo Horizonte: Maio de 1976. Disponível em https://www.direito.ufmg.br/revista/index.php/revista/article/viewFile/1445/1374 Acessado em: 20/12/2017.

SOUSA NETO, Gabriela de, e SILVA, Larissa Carneiro. A livre concorrência e a função repressiva do CADE. Disponível em 09/01/208 no endereço eletrônico https://jus.com.br/artigos/53126/a-livre-concorrencia-e-a-funcao-repressiva-do-cade 